\title{
CASO ODEBRECHT EM ANGOLA: AUTOCOMPOSIÇÃO EM PROCESSO COLETIVO TRANSNACIONAL ${ }^{1}$
}

\section{ODEBRECHT CASE IN ANGOLA: SETTLEMENT IN TRANSNATIONAL COLLECTIVE PROCESS}

Carlos Henrique Bezerra Leite Pós-Doutor em Democracia e Direitos Humanos pelo Ius Gentium Conimbrigae/Centro de Direitos Humanos da Faculdade de Direito da Universidade de Coimbra-Portugal. Doutor e Mestre em Direito (PUC/SP). Professor de Direitos Humanos Sociais e Metaindividuais e Direito Processual do Trabalho da Faculdade de Direito de Vitória-FDV (Doutorado, Mestrado e Graduação). Desembargador do TRT da 17 Região/ES (aposentado). Advogado e Consultor Jurídico. Foi Professor Associado do Departamento de Direito da UFES. Professor convidado de diversas Escolas Judiciais da Justiça do Trabalho. Titular da Cadeira n. 44 da Academia Brasileira de Direito do Trabalho. Ex-Procurador Regional do Ministério Público do Trabalho/ES. Ex-Diretor da Escola Judicial do TRT/ES. Ex-Procurador do Município de Vitória-ES. Vitória/ES. www.professorbezerraleite.com.br. E-mail: chbezerraleite@gmail.com.

\section{Graziela Argenta Zaneti}

Doutoranda na Faculdade de Direito de Vitória - PPGD FDV. Mestre em Direito Processual Civil na Universidade Federal do Espírito Santo - UFES; Especialista em Direito Urbano Ambiental pela FMP - Fundação Escola Superior do Ministério Público do Rio Grande do Sul. Promotora de Justiça

\footnotetext{
${ }^{1}$ Artigo recebido em 02/07/2021 e aprovado em 11/10/2021.
} 
no Estado do Espírito Santo. Vitória/ES. E-mail: grazielazaneti@gmail.com.br

RESUMO: O problema da efetividade das decisões em ações coletivas transnacionais sempre foi um desafio a ser superado. A proposta deste artigo é, a partir do estudo do caso Odebrecht em Angola, pensar a autocomposição em litígios coletivos transnacionais como forma de superar dificuldades resultantes dos limites impostos pelas jurisdições de cada ordenamento jurídico em situações que não se limitam a uma só fronteira nacional. Isso inclui uma gestão do processo coletivo transnacional que se inicia desde a escolha da jurisdição concorrente mais adequada para desenvolvimento da ação, passa pelo tipo de pedido ou pedidos a serem tratados, e se preocupa com uma completude probatória que favoreça à resolução autocompositiva do conflito transnacional. Os acordos, nesse sentido, representam uma importante ferramenta no auxílio para a efetivação de direitos coletivos transnacionais em um cenário de lacuna de acesso à justiça transnacional.

PALAVRAS-CHAVE: Processo coletivo transnacional; jurisdição internacional; autocomposição; efetivação de direitos coletivos transnacionais; gerenciamento; lacuna de acesso à justiça transnacional.

ABSTRACT: The problem of the effectiveness of decisions in transnational collective actions has always been a challenge to be overcome. The purpose of this article is, based on the study of the Odebrecht case in Angola, to think settlements in transnational collective disputes as a way of overcoming difficulties resulting from the limits imposed by the jurisdictions of each legal system in situations that are not limited to a single national border. This includes the management of the transnational collective process that begins with the choice of the most appropriate jurisdiction for the development of the action, goes through the type of claim to be dealt with, and concerns itself with completeness of the evidence that favors the settlement. Settlements, in this sense, represent an important tool in helping to enforce transnational collective rights in transnational-access-to-justice gap. 
KEYWORDS: Transnational collective process; jurisdiction; settlements; effectiveness of collective transnational rights; case management; transnational-access-to-justice gap.

\section{INTRODUÇÃO}

A solução consensual dos conflitos vem ganhando cada vez mais uma posição de destaque frente à justiça estatal clássica. Essa mudança do acesso aos tribunais para o acesso ao Direito não é diferente nos processos coletivos, especialmente nas ações coletivas, cujos litígios tendem a ser mais complexos.

Nos litígios coletivos transnacionais, que tratam de situações jurídicas que não se limitam ao território de um país, a busca por uma justiça que seja capaz de pacificar e remendar o tecido social, com menor custo e com menor duração, tutelando de forma adequada situações jurídicas transnacionais também é uma realidade cada vez mais comum.

A definição da jurisdição mais adequada que irá tratar do caso nos processos coletivos transnacionais, dentre os ordenamentos jurídicos concorrentes, sempre foi um ponto de partida a ser superado para o acesso à justiça substancial de situações jurídicas em que um único fato pode afetar uma pluralidade de atores vinculados a diferentes ordenamentos jurídicos.

Mas não só, a concretização da tutela obtida em um país através desses processos coletivos transnacionais, por vezes, necessita de reconhecimento e execução em outro ordenamento jurídico, advindo, não raras às vezes, obstáculos instransponíveis à efetivação da tutela obtida, comumente decorrentes de problemas no reconhecimento de sentença estrangeira e execução, especialmente quando se tratam de ações coletivas opt out (semelhantes às class actions norte-americanas).

Nesse cenário de real dificuldade dos litígios coletivos transnacionais, a superação de muitos problemas para efetivação das decisões que envolvem diferentes ordenamentos jurídicos pode ser pensada a partir da autocomposição.

Pois bem, este trabalho procurará, a partir da utilização de uma metodologia hipotético-dedutiva, tendo como pano de fundo o caso Odebrecht em Angola ${ }^{2}$, analisar as

\footnotetext{
${ }^{2}$ Este caso foi tratado já foi tratado por ZANETI, Graziela Argenta. Jurisdição adequada para os processos coletivos transnacionais. São Paulo: RT, 2020, p. 184-185, mas não em relação à perspectiva da
} 
vantagens dos meios autocompositivos na resolução de conflitos em processos coletivos transnacionais, especialmente como forma de efetivação dos direitos face às dificuldades atinentes à jurisdição de diferentes ordenamentos jurídicos.

O tema da autocomposição em litígios coletivos transnacionais tem uma relevância teórica, porque, muito embora seja comum em outros ordenamentos jurídicos que dispõem de ações coletivas (semelhantes às class actions), tais como os Estados Unidos e o Canadá, em nosso ordenamento, ainda é um assunto pouco estudado. Nesse sentido, o estudo da autocomposição no Caso Odebrecht em Angola ganha destaque porque se trata de um acordo ocorrido em processo coletivo transnacional no Brasil.

Igualmente, esse tema conta com uma relevância prática por estar cada vez mais presente aos operadores do direito, em especial, ao Ministério Público - protagonista, no Brasil, da tutela dos direitos coletivos.

O fortalecimento de uma dogmática nacional sobre acordos e, por consequência, de sua aplicação aos direitos coletivos transnacionais, é um passo a ser dado em direção à concretização da tutela de direitos coletivos transnacionais, com a obtenção de decisões mais efetivas, inclusive para a tutela de direitos humanos dos trabalhadores.

\section{DESCRIÇÃO DO CASO}

Utilizar-se-á o caso Odebrecht em Angola que resultou em um acordo de $\mathrm{R} \$$ 30.000.000,00 (trinta milhões de reais), além da assunção de obrigações de não fazer na maior ação por trabalho escravo da história do Brasil ${ }^{3}$.

Neste caso, o Ministério Público do Trabalho propôs Ação Civil Pública ${ }^{4}$ perante a $2^{\circ}$ Vara do Trabalho em Araraquara, pleiteando, em síntese, a condenação da Construtora Norberto Odebrecht S/A., da Olex Importação e Exportação S.A. e da Odebrecht Agroindustrial S.A. (antes denominada ETH Bioenergia), em obrigações de fazer e de não fazer, bem como indenizações por danos morais coletivos por contratação irregular

autocomposição. Igualmente parte dos conceitos tratados neste artigo, foram tratados no referido livro. A perspectiva, entretanto, agora é a análise da autocomposição.

${ }^{3}$ Conforme consta na página do MPT https://mpt.mp.br/pgt/noticias/odebrecht-pagara-r-30-mi-para-encerraracao-por-trabalho-escravo.

${ }^{4}$ Ação Civil Pública no 10230-31.2014.5.15.0079 do Ministério Público do Trabalho. 
(arregimentar trabalhadores de forma irregular com aliciamento, merchandage $e^{5}$ e tráfico internacional de seres humanos) e por manter trabalhadores em Angola, em desrespeito a direitos trabalhistas e com cerceamento da liberdade de ir e vir, mediante violência (redução à condição análoga à de escravo), bem como pelo beneficiamento irregular de financiamento do BNDES para aplicação em obras em Angola.

No caso, parte dos danos (aliciamento e tráfico internacional de trabalhadores) ocorreu no Brasil e parte em Angola (submissão de trabalhadores à condição análoga a de escravo).

Em Angola, cerca de 2.100 empregados angolanos e brasileiros (cerca de 400) foram submetidos à tal situação degradante nas obras para a implantação da usina de açúcar em 2014, pertencente, formalmente, à empresa angolana Biocom/Companhia de Bioenergia de Angola Ltda.

A Construtora Norberto Odebrecht S.A. (CNO), principal empresa do grupo Odebrecht, para eximir-se de qualquer responsabilidade com relação aos gravíssimos fatos ocorridos em Angola, sempre referiu que a Biocom/Companhia de Bioenergia de Angola Ltda. era uma empresa estrangeira independente, embora integrante do grupo Odebrecht. A CNO afirmava nunca ter tido qualquer relação ou ingerência na empresa estrangeira Biocom, tampouco nas obras de construção da usina. As cláusulas contratuais constantes dos contratos comerciais eximiam qualquer responsabilidade da CNO. Além disso, ela alegava a incompetência da Justiça Brasileira, em razão de a Biocom ser uma empresa estrangeira.

As provas produzidas no inquérito civil demonstraram, contudo, que, no plano da realidade, havia uma conexão business-related entre as empresas, sendo que a construção da usina da Biocom foi um empreendimento direto e exclusivo da Construtora Norberto Odebrecht e da Odebrecht Agroindustrial, havendo apenas separação formal das responsabilidades.

\footnotetext{
5 "Marchandage" é uma expressão francesa cunhada no século XIX para nominar situações em que um trabalhador era contratado por intermédio de um mercador de força de trabalho, cujo negócio consistia em lucrar com o trabalho de terceiros que locava. Essa prática foi abolida pela Declaração de Filadélfia, ratificada pelo Brasil, em seu artigo $1^{\circ}$, que reafirmou o princípio de que o trabalho não é uma mercadoria. Contudo, a má prática da "marchandage" continua existindo, em especial no Brasil, onde aflora toda espécie de "terceirização" de mão-de-obra (que, diferente do que alguns propagam, em nada se parece com as práticas anglo-saxônicas de terceirização, denominadas "outsourcing" e "offshoring"). Ação trabalhista $\mathrm{n}^{\circ}$ 0000285-67.2012.5.03.0097, $4^{\mathrm{a}}$ Vara do Trabalho de Coronel Fabriciano.
} 
Após condenação das empresas rés em primeiro grau de jurisdição, acordaram as partes, no dia 3 de março de 2017, no Tribunal Regional do Trabalho da $15^{\text {a }}$ Região, para fim de dar quitação à indenização pleiteada na inicial da ação civil pública, que as empresas pagariam, de forma solidária, $\mathrm{R} \$ 30.000 .000,00$ (trinta milhões de reais), além da assunção de obrigações de não fazer ${ }^{6}$.

\section{O CASO ODEBRECHT EM ANGOLA COMO PROCESSO COLETIVO}

\section{TRANSNACIONAL}

No que tange à delimitação do objeto deste artigo, importante referir, inicialmente, alguns conceitos para situar o tema em análise.

$\mathrm{O}$ art. $81^{7}$ do CDC traz a estrutura dos direitos coletivos lato sensu, como eles podem ser veiculados em juízo, prevendo três tipos: direitos difusos, direitos coletivos stricto sensu e direitos individuais homogêneos, que serão identificados de acordo com a pretensão posta em juízo. ${ }^{8}$

\footnotetext{
6 "1.1. Jamais vir a realizar, promover, estimular ou contribuir com a submissão de trabalhadores à condição análoga à de escravo, sob pena de multa no importe de $\mathrm{R} \$ 100.000,00$, por trabalhador; 1.2. Jamais vir a realizar, promover, estimular ou contribuir com aliciamento nacional e/ou internacional de trabalhadores, sob pena de multa, no importe $\mathrm{R} \$ 100.000,00$, por trabalhador; 1.3. Não utilizar em seus empreendimentos no exterior mão de obra contratada no Brasil mediante contrato de trabalho enviado ao país estrangeiro sem o visto de trabalho já concedido pelo governo do local, sob pena de multa, no importe de $\mathrm{R} \$ 60.000,00$, por trabalhador; 1.4. Não realizar, promover; contribuir ou se aproveitar da intermediação de mão de obra (marchandage), inclusive com o envolvimento de aliciadores, intermediadores ou "gatos", em desacordo com a lei, salvo em caso de trabalho temporário, com os contornos admitidos pela Lei 6.019 e de serviço de facilitação à colocação no mercado de trabalho realizados pelo SINE (Sistema Nacional de Empregos) sob pena de multa, no importe de $\mathrm{R} \$ 50.000,00$, por trabalhador." (...) Os valores obtidos com o acordo serão destinados a projetos, initiativas ou campanhas que revertam em benefício da coletividade, mediante aprovação conjunta do Ministério Público do Trabalho e do Tribunal Regional do Trabalho da $15^{\mathrm{a}}$ Região".

7 "Art. 81. A defesa dos interesses e direitos dos consumidores e das vítimas poderá ser exercida em juízo individualmente, ou a título coletivo. Parágrafo único. A defesa coletiva será exercida quando se tratar de: I interesses ou direitos difusos, assim entendidos, para efeitos deste código, os transindividuais, de natureza indivisível, de que sejam titulares pessoas indeterminadas e ligadas por circunstâncias de fato; II - interesses ou direitos coletivos, assim entendidos, para efeitos deste código, os transindividuais, de natureza indivisível de que seja titular grupo, categoria ou classe de pessoas ligadas entre si ou com a parte contrária por uma relação jurídica base; III - interesses ou direitos individuais homogêneos, assim entendidos os decorrentes de origem comum."

${ }^{8}$ NERY JR., Nelson. Código Brasileiro de Defesa do Consumidor: comentado pelos autores do anteprojeto. Rio de Janeiro: Forense Universitária. 1998, p.778; DIDIER JR., Fredie; ZANETI JR., Hermes. Curso de Direito Processual Civil. Vol. 4, p. 89.
} 
Os processos coletivos podem ser pensados a partir da formação do grupo, numa classificação que diz respeito à necessidade ou não de uma conduta ativa dos membros para a formação do grupo.

Na técnica coletiva opt out, o grupo forma-se independentemente da conduta ativa de cada um dos membros do grupo (presume-se a inclusão do membro do grupo no litígio, condicionando-se a exclusão do membro a uma manifestação expressa nesse sentido ${ }^{9}$ (tutela um, tutela todos). Essa é a técnica dominante das ações coletivas brasileiras que tem como paralelo às class actions americanas. ${ }^{10}$

Na técnica coletiva opt in, por sua vez, a formação do grupo ocorre a partir de uma manifestação ativa de cada indivíduo para que haja a tutela de seu direito, seja através da iniciativa do autor, individualmente, em ajuizar sua própria ação que, posteriormente, em face de outras ações repetitivas, são agregadas para fins de julgamento único (casos repetitivos). ${ }^{11}$

Na técnica híbrida, por fim, a técnica coletiva base opt out, admite previsão opt in para delimitar determinadas situações, tais como para restringir o acesso a membros estrangeiros $^{12}$, por exemplo. Igualmente pode ser utilizada para regular situação indenizatória de sub-grupos conflitantes dentro de um grupo maior, exigindo para eles um comportamento ativo (opt in) nesses casos.

Nesse sentido, "processo coletivo é aquele em que se postula um direito coletivo lato sensu (situação jurídica coletiva ativa) ou se afirme a existência de uma situação jurídica coletiva passiva (deveres individuais homogêneos, p. ex.) de titularidade de um grupo de

\footnotetext{
${ }^{9}$ GIDI, Antonio. A Class Action como instrumento de tutela coletiva dos direitos. São Paulo: Revista dos Tribunais, 2007, p. 292.

${ }^{10}$ ZANETI, Graziela Argenta. Jurisdição adequada para os processos coletivos transnacionais. São Paulo: RT, 2020, p. 175-182.

${ }^{11}$ Podem-se citar, no common law, como forma de litígios opt in, a Multidistrict Litigation (MDL) do direito Norte-americano e a Multi-party Litigation da Inglaterra (Group Litigation Order - GLO). Sobre o tema ver ANDREWS Neil. "Multi-Party Proceedings in England: Representative and Group Actions". 11 Duke Journal of Comparative \& $\quad$ International Law 249-268 $\quad$ (2001), disponível em http://scholarship.law.duke.edu/djcil/vol11/iss2/5, acesso em 15.7.2017; HODGES, Christopher J. S. Multiparty actions. Oxford: Oxford University Press, 2001. Incluem-se também nessa modalidade de litígios opt in, o modelo alemão das Musterverfahren e o Incidente de Resolução de Demandas Repetitivas (IRDR), no Brasil, iniciado com o CPC/15. CABRAL, Antônio do Passo. "Incidente de Resolução de demandas Repetitivas". Comentários ao Novo Código de Processo Civil. Antonio do Passo Cabral e Ronaldo Cramer (coord.). Rio de Janeiro: Forense, 2015.

${ }^{12}$ Idem, ibidem; BASSETT, Debra Lyn. "Class Action Silence". Boston University Law Review, Vol. 94, No. 4, 2014, disponível em: https://ssrn.com/abstract=2533776, acesso em 10.7.2017; MONESTIER, Tanya J.. Transnational Class Actions and the Illusory Search for Res Judicata, p. 5.
} 
Revista Eletrônica de Direito Processual - REDP.

Rio de Janeiro. Ano 16. Volume 23. Número 1. Janeiro a Abril de 2022

Periódico Quadrimestral da Pós-Graduação Stricto Sensu em Direito Processual da UERJ

Patrono: José Carlos Barbosa Moreira (in mem.). ISSN 1982-7636. pp. 213-235

www.redp.uerj.br

pessoas"13, sendo a ação coletiva no Brasil ${ }^{14}$ uma espécie do gênero processo coletivo que tem a característica de ser, predominantemente, uma técnica coletiva opt out, isto é, o grupo (sujeito de direito titular da situação jurídica coletiva) é formado independentemente da conduta ativa de cada um dos membros do grupo.

Os processos coletivos transnacionais, por sua vez, podem ser entendidos como aqueles em que podem ocorrer, ao menos, as seguintes circunstâncias para a tutela de situações jurídicas coletivas: a) o grupo formado por membros no polo ativo ou passivo estrangeiros (foreign plaintiffs $)^{15}$; b) uma demanda ajuizada contra demandado estrangeiro ${ }^{16}$, normalmente uma corporação transnacional, com estabelecimentos comerciais em mais de um país; c) quando o dano ou ilícito ultrapasse as fronteiras nacionais. ${ }^{17}$ Esses elementos podem concorrer, quer dizer, estarem todos ou pelo menos dois presentes ao mesmo tempo, ou, podem se dar de forma isolada. Basta um elemento para que se forme um processo coletivo transnacional. ${ }^{18}$

${ }^{13}$ DIDIER JR., Fredie; ZANETI JR. Hermes. "Conceito de Processo Jurisdicional Coletivo". RePro, São Paulo: RT, nº 229 , mar. 2014, p. 273-280;

${ }^{14}$ Também definido como sistema do acesso metaindividual. LEITE, Carlos Henrique Bezerra. Curso de Direito Processual do Trabalho. $19^{\mathrm{a}}$ ed. São Paulo: Saraiva, 2021, item 5.4.2.7. Para maior aprofundamento do tema da ação trabalhista metaindividual ver LEITE, Carlos Henrique Bezerra. Manual de Direitos Humanos. 3. ed. São Paulo: Atlas, 2014. v. 1.

${ }^{15}$ MONESTIER, Tanya J.. "Transnational Class Actions and the Illusory Search for Res Judicata", p. 3.

${ }^{16}$ PINNA, Andrea. "Recognition and Res Judicata of U.S. Class Action Judgments in European Legal Systems", p. 31.

${ }^{17}$ Conforme Whytock, "defining "transnational litigation" as litigation having connections to more than one country, and noting that these connections may be territorial when the activity or its effects touch the territory of more than one country, or based on legal relationships between a country and the actors engaged in or affected by that activity, such as citizenship". WHYTOCK, Christopher A. "The Evolving Forum Shopping System", 96 Cornell L. Rev. 481, 486 (2011). Disponível em http://scholarship.law.cornell.edu/cgi/viewcontent.cgi?article=3195\&context=clr, acesso em 1.7.2017. Considera-se como litígios transfonteiriços aqueles cujo dano ocorre simultaneamente em mais de um ordenamento jurídico; ZANETI JR, Hermes; BORGES, Orlindo Francisco; CARDOSO, Juliana Provedel. "Ações Coletivas Transnacionais para a tutela de danos ambientais: o caso Chevron (HSE no 8542)". Revista de Direito Ambiental. São Paulo: RT, ano 21, $\mathrm{n}^{\circ}$ 84, out/dez, 2016; TIBURCIO, Carmen. Extensão e limites da Jurisdição Brasileira. Competência Internacional e Imunidade de Jurisdição, p. 61. MOSCHEN, Valesca Raizer Borges; ZANETI, Graziela A.. "Processo Internacional Transfronteiriço: os litígios que não respeitam fronteiras - da soberania à tutela dos direitos". In: Bruno Manoel Viana; Valesca Raizer Borges Moschen;Valter Moura do Carmo. (Org.). Direito Internacional II. $1^{\mathrm{a}}$ ed. Florianópolis: CONPEDI, 2016, v. 1, p. 80-95; Sobre a definição do conceito de Direito Processual Civil Transnacional ver: HILL, Flávia Pereira. $O$ direito processual transnacional como forma de acesso à justiça no Século XXI: os reflexos e desafios da sociedade contemporânea para o direito processual civil e a concepção de um título executivo transnacional. Rio de Janeiro: GZ Editora, 2013, p. 58-60.

${ }^{18}$ ZANETI, Graziela Argenta. Jurisdição adequada para os processos coletivos transnacionais. São Paulo: RT, 2020, p. 68. 
O caso Odebrecht em Angola pode ser considerado um exemplo de ação coletiva transnacional, já que i) o grupo de direitos difusos tutelado incluiu nacionais e estrangeiros; ii) a empresa onde ocorreram os fatos extraterritorias era uma empresa estrangeira com conexão business-related à uma corporação transnacional (parent company) brasileira, responsável pelos atos cometidos pela empresa localizada no exterior; iii) o dano ou ilícito ultrapassou fronteiras nacionais.

No caso Odebrecht em Angola o pedido da ação buscou a tutela de direitos difusos, isto é, uma indenização coletiva por dano moral coletivo (e não para o direito individual de cada membro - tutela de direitos individuais homogêneos), com destinação de valores a projetos, iniciativas ou campanhas que revertam em benefício da coletividade, além da assunção de obrigações de não-fazer, ambas para tutelar direitos difusos.

A formação do grupo nessa ação coletiva se deu de forma opt out, isto é, todos que estavam naquela situação foram tutelados (nacionais e estrangeiros) de forma difusa. Os pedidos constantes da inicial, pelos quais se define o tipo de tutela (no caso para direitos difusos), foram para a tutela de pessoas indeterminadas (nacionais e estrangeiros). Houve assunção pela corporação transnacional de obrigações de não cometer mais condutas indevidas tanto no Brasil, quanto no exterior.

A solução no caso Odebrecht em Angola ocorreu por meio de autocomposição judicial realizada, após condenação das empresas rés em primeiro grau de jurisdição, no dia 3 de março de 2017, no Tribunal Regional do Trabalho da $15^{\text {a }}$ Região.

\section{A JURISDIÇÃO INTERNACIONAL COMO ÓBICE NA TUTELA DOS DIREITOS COLETIVOS TRANSNACIONAIS}

Os processos coletivos transnacionais, por envolverem situação jurídicas que não se limitam a um só ordenamento jurídico (jurisdição), sempre tiveram dificuldades de implementação e efetivação das decisões, quando necessário o reconhecimento da sentença e execução em outro país ${ }^{19}$.

\footnotetext{
${ }^{19}$ HILL, Flávia Pereira. A antecipação da tutela no processo de homologação de sentença estrangeira. Rio de Janeiro: GZ Editora, 2010, p. 119-122.
} 
Através da jurisdição ${ }^{20}$, identifica-se o país (ou os países) que pode decidir uma causa com elemento de estraneidade. Diante de jurisdições concorrentes, isto é, dois ou mais países com jurisdição para determinada causa, cabe à parte autora decidir onde propor a ação. Uma escolha sofisticada de onde propor a ação implica considerar os três referidos pilares do Direito Internacional Privado, isto é, as peculiaridades do direito processual de cada uma das jurisdições concorrentes (por exemplo, a existência de ação coletiva opt out como ocorre no Brasil), as diferenças do direito substancial aplicável (lex causae), além da probabilidade de sucesso no reconhecimento e execução no estrangeiro, se necessários.

Nos litígios coletivos transnacionais, após a definição da jurisdição, que é um tema afeto ao Direito Internacional Privado, e não será objeto deste artigo, o processo coletivo transnacional fixa-se em determinado ordenamento jurídico.

Assim, há uma grande relevância na escolha sofisticada da jurisdição concorrente a ser proposta a ação coletiva no sentido de facilitar a tutela dos direitos coletivos envolvidos, mas não só.

O gerenciamento do processo coletivo transnacional é o ponto de destaque para a efetividade na tutela dos direitos.

Essa gestão do processo coletivo transnacional inclui um gerenciamento processual que busque evitar problemas futuros de reconhecimento e execução de sentença em outro ordenamento jurídico ${ }^{21}$. Quais pedidos (tipos de tutela) devem constar na ação coletiva que facilitarão a efetivação dos direitos com menor obstáculos possíveis, inclusive evitando a necessidade de reconhecimento e execução em outro ordenamento jurídico? Trata-se, portanto, de um gerenciamento que se inicia desde a escolha da jurisdição concorrente, inclui

\footnotetext{
${ }^{20}$ Trata-se de tema relacionado à jurisdição no plano internacional, e não à competência internacional, embora a doutrina já tenha adotado a prática de se utilizar o termo "jurisdição" e "competência internacional" indistintamente, o que também será feito ao longo desse trabalho. Segundo Carmen Tiburcio, fala-se em jurisdição, enquanto atributo decorrente da soberania do Estado para delimitar quais são as hipóteses que podem ser submetidas a julgamento em seu território. Difere-se da competência internacional, em que a jurisdição se organiza entre Estados soberanos, a exemplo do Regulamento 1215/2012 da União Europeia, que define entre os países membros aqueles que irão apreciar uma controvérsia. Entretanto, também a autora, mesmo considerando as distinções terminológicas, utiliza-se das expressões "jurisdição" e "competência internacional" indistintamente. TIBURCIO, Carmen. Extensão e Limites da Jurisdição Brasileira: competência internacional e imunidade de jurisdição, p.21-24; Nádia de Araújo também utiliza as expressões "jurisdição" e "competência internacional" indistintamente. ARAÚJO, Nádia de. Direito Internacional Privado. Teoria e Prática Brasileira. $1^{a}$ ed. Porto Alegre: Revolução, eBook, 2016.

${ }^{21}$ Sobre o tema da gestão adequada de conflitos ver GORETTI SANTOS, Ricarco. Gestão Adequada de Conflitos: do diagnóstico à escolha do método adequado para cada caso concreto. 1. ed. Salvador: JusPodivm, 2019. v. 1.
} 
tipo de pedido da ação coletiva que favoreça à efetivação da tutela transnacional e, especialmente, que considera a possibilidade da autocomposição na resolução do conflito.

A resolução autocompositiva da ação coletiva transnacional tem a vantagem de facilitar a superação dos limites da jurisdição de cada país, que é o principal óbice à efetivação dos direitos coletivos transnacionais. Isso porque o reconhecimento (e a execução) de sentença em ações coletivas em um ordenamento jurídico estrangeiro significa comumente problema de duração razoável do processo, quando não de reconhecimento da sentença coletiva estrangeira. Em verdade, esse não reconhecimento decorre da rejeição de alguns ordenamentos jurídicos à técnica coletiva opt out, ou ainda pelo entendimento de não ser cabível a regulação de matéria de direito público extraterritorialmente. ${ }^{22}$

Nesse cenário, a autocomposição em processos coletivos transnacionais ganha destaque e deve ser pensada justamente como forma de evitar decisões judiciais que poderiam ter maior dificuldade de se tornarem efetivas em outro ordenamento jurídico, a depender de um reconhecimento ou execução de sentença estrangeira resultantes de ações coletivas transnacionais.

O acordo nos processos coletivos transnacionais pode, portanto, representar grande auxílio na superação da barreira da jurisdição internacional, facilitando a implementação de direitos coletivos transnacionais.

Por exemplo, a modificação comportamental, que é um dos objetivos principais das ações coletivas e também das transnacionais, isto é, o uso da justiça civil para deter condutas prejudiciais, através da corrective justice no caso do ilícito coletivo e da função deterrente ${ }^{23}$, por meio da efetiva punição da conduta, pode ser alcançada com a assunção de compromissos transnacionais pela corporação (parent company - empresa-mãe) localizada

\footnotetext{
${ }^{22}$ BUSCHKIN, Ilana T. "The Viability of Class Action Lawsuits in a Globalized Economy - Permitting Foreign Claimants to Be Members of Class Action Lawsuits in the U.S. Federal Courts". Cornell Law Review, Vol. 90, 2005. Disponível em SSRN: https://ssrn.com/abstract=2084220, acesso e 11.7.2017, p. 1575-1582.

23 "A simples possibilidade da tutela coletiva, e da consequente responsabilidade civil em massa, faz com que potenciais infratores se sintam desencorajados de praticar condutas ilícitas e resistam à tentação de obter lucros fáceis em detrimento de direitos e interesses de uma coletividade que, de outra forma, estaria completamente indefesa e vulnerável (deterrence)". GIDI, Antonio. A Class Action como instrumento de tutela coletiva dos direitos. São Paulo: Revista dos Tribunais, 2007, p. 36. Cita ainda como técnicas utilizadas pela função deterrente os minimal damages, double damages, treble damages e os punitive damages. Segundo o GARNER, Bryan A. Black's Law Dictionary, $2^{a}$ pocket ed. West Group, 2001, punitive damages é "damages awarded in addition to actual damages when the defendant acted with recklessness, malice, or deceit"; Segundo o GARNER, Bryan A. Black's Law Dictionary, $2^{a}$ pocket ed. West Group, 2001, punitive damages é "damages awarded in addition to actual damages when the defendant acted with recklessness, malice, or deceit"; treble damages é "damages that, by statute, are three times the amount that the fact-finder determinines is owed".
} 
em território nacional, o que representa uma regulação de conduta para além das fronteiras nacionais ${ }^{24}$. Isso tem, por si só, uma grande efetividade transnacional, pois essas corporações têm ramificações por diversos países e a assunção de um compromisso regulativo por meio de acordo pode alcançar efetividade extraterritorial (fora do ordenamento jurídico), diminuindo dificuldades advindas de jurisdição internacional.

É comum empresas transnacionais terem conexão business-related com empresas localizadas em países mais vulneráveis (muitos destituídos de instrumentos processuais adequados para a tutela de direitos coletivos) e usarem essas empresas para fazerem a "parte suja" da atividade econômica. São empresas formalmente independentes, mas, de fato, ligadas fortemente por uma conexão business-related com a empresa-mãe. É através dessa conexão (prova de uma conexão substancial entre as empresas) que pode haver a atração para a empresa-mãe da responsabilidade por atos ilegais cometidos em território estrangeiro por empresas que servem como braços à corporação transnacional. A assunção de obrigações injuncionais (de fazer ou não-fazer) pela empresa-mãe por meio da autocomposição tem potencial de alcançar efetividade além-fronteiras, sem a necessidade de envolver a jurisdição outro ordenamento jurídico.

No acordo realizado no caso Odebrecht em Angola, a assunção pela parent company (Odebrecht) de obrigações de não fazer mais condutas ilegais relacionadas ao direito coletivo do trabalho, protegendo difusamente trabalhadores nacionais e estrangeiros das condutas ilegais das empresas implicou uma regulação transnacional da atividade econômica. Foram obrigações assumidas em nosso ordenamento jurídico e que terão efeitos aqui, em Angola e em qualquer outro país.

No caso em análise, como se referiu, houve um gerenciamento da ação coletiva transacional desde o momento da formulação dos pedidos, pois não houve pedidos de indenização para direitos individuais homogêneos, somente pedido indenizatório para o direito difuso violado (direito do trabalho de nacionais e estrangeiros).

A utilização da técnica coletiva opt out (tutela um, tutela todos) foi pensada para obter maior abrangência à tutela regulatória, sem necessariamente envolver outro

\footnotetext{
${ }^{24}$ BUXBAUM, Hannah L. "Transnational Regulatory Litigation", passim; BUXBAUM, Hannah L. "Class Actions, Conflict and the Global Economy". Indiana Journal of Global Legal Studies, Vol. 21, Summer 2014; Indiana Legal Studies Research Paper $\mathrm{n}^{\circ}$ 301, passim, disponível em SSRN: https://ssrn.com/abstract=2495521, acesso em 12.7.2017.
} 
ordenamento jurídico (jurisdição). Isso porque as ações coletivas que envolvem pedidos relacionados a direitos individuais homogêneos (indenizações) e que são transnacionais em razão de o grupo ser formado por membros estrangeiros (foreign plaintiffs) tendem a ser mais complexas.

As técnicas coletivas utilizadas em caso de pedido que envolva direito individual homogêneo variam de opt out (presume-se a inclusão e todos os membros do grupo), opt in (inclusão do membro depende de manifestação ativa da vontade de cada um) ou híbrida (mescla as duas técnicas).

No Brasil, contudo, como os direitos fundamentais individuais e coletivos se somam, não se subtraem ${ }^{25}$, ações individuais indenizatórias podem ser propostas concomitantemente à ação coletiva (não há litispendência entre ação coletiva e individual), bem como ações individuais podem ser propostas em caso de improcedência da ação coletiva (coisa julgada secundum eventum litis) $)^{26}$.

Essa independência entre as tutelas coletiva e individual no ordenamento jurídico brasileiro é uma vantagem de acesso à justiça em nosso ordenamento jurídico ${ }^{27}$ e permite que haja um gerenciamento da tutela coletiva de modo a fracionar as tutelas de forma estratégica sem que haja prejuízo à tutela dos direitos, quando o caso concreto indicar que isso possa representar vantagem à efetivação dos direitos. Essa foi a opção tomada no caso Odebrecht em Angola. Os direitos individuais homogêneos permanecem hígidos para gerar novas demandas individuais, ou outra demanda coletiva para a tutela desses direitos com técnica opt out, opt in, ou híbrida.

\section{AUTOCOMPOSIÇÃO COMO FERRAMENTA PARA EFETIVIDADE DOS PROCESSOS COLETIVOS TRANSNACIONAIS}

\footnotetext{
${ }^{25}$ ZANETI JR., Hermes. O “novo" mandado de segurança coletivo. Salvador: Jus Podivum, 2013, p. 261-262. ${ }^{26}$ DIDIER JR., Fredie; ZANETI JR., Hermes. Curso de Direito Processual Civil. Processo Coletivo. Vol. 4. $15^{\mathrm{a}}$ ed. Salvador: JusPodivm, 2021, p. 509-515;

${ }^{27}$ No Brasil há um sistema metaindividual (órgãos públicos, associação civil e cidadão) de acesso à justiça que combina o sistema publicista, o privatista e o associacionista, mas o destaque é o Ministério Público LEITE, Carlos Henrique Bezerra. "Acesso coletivo à justiça como instrumento para efetivação dos direitos humanos: por uma nova mentalidade". Revista do Tribunal Regional do Trabalho da $15^{a}$ Região, n. 35, 2009, p. 94. , disponível em https://juslaboris.tst.jus.br/bitstream/handle/20.500.12178/104849/2009_leite_carlos_acesso_coletivo.pdf?se quence $=1 \&$ isAllowed=y, acesso em 21.4.2021.
} 
Nosso ordenamento jurídico, a partir do Novo Código de Processo Civil (Lei 13.105/2015), propõe a solução judicial como ultimo ratio $^{28}$, ao estabelecer que a conciliação, a mediação e outros métodos de solução consensual de conflitos serão estimulados por juízes, advogados, defensores públicos e membros do Ministério Público, inclusive no curso do processo judicial (art. $3^{\circ}, \S 3^{\circ}$ do CPC) através do princípio do estímulo à autocomposição.

Os acordos podem ser materiais, processuais ou mistos. Os acordos podem ocorrer extrajudicialmente, ou após o ajuizamento da ação coletiva, já em juízo. Os acordos podem até mesmo estabelecer como ocorrerá a fase de execução em caso de descumprimento da autocomposição. A autocomposição é hoje, portanto, uma realidade, também nos litígios coletivos transnacionais, como vimos.

Esse process pluralism tem a vantagem de não ser vendido mais em um único tamanho ${ }^{29}$, podendo ser adaptado às necessidades de cada uma das tutelas de direito. No caso de acordos em direitos coletivos transnacionais, a tutela desses direitos tem características peculiares que indicam que a autocomposição pode ser uma saída vantajosa para evitar problemas relacionados à jurisdição internacional.

A efetivação da tutela coletiva transnacional relaciona-se diretamente à necessidade de não se criar entraves desnecessários à realização do direito. Se "o direito existe para se realizar. A realização é a vida e a verdade do direito, é o próprio direito. O que não se traduz em realidade (...) é um direito meramente aparente, nada mais que palavras vazias (...)"30.

\footnotetext{
${ }^{28}$ DIDIER JR., Fredie; ZANETI JR., Hermes. Curso de Direito Processual Civil. Processo Coletivo. Vol. 4. $14^{a}$ ed. Salvador: JusPodivm, 2020, p. 376. Ideias também defendidas por Paula Costa e Silva (COSTA E SILVA, Paula. A Nova Face da Justiça. Os Meios Extrajudiciais de Resolução de Controvérsias. Lisboa: Coimbra Editora, 2009, p. 19/21). Em sentido próximo "a leitura atual do princípio do acesso à justiça [...] é hoje compreensiva da justiça arbitral e da conciliativa, incluídas no amplo quadro da política judiciária e consideradas como espécies de exercício jurisdicional (...) integram o conceito de jurisdição (...) atividade, função e garantia, voltada ao acesso à justiça e à pacificação dos conflitos", portanto, defendendo que o conceito de acesso à justiça previsto no art. $5^{\circ}, \mathrm{XXXV}, \mathrm{CF} / 1988$ e o conceito de jurisdição se estendem atualmente para englobar a autocomposição e a arbitragem, cf. GRINOVER, Ada Pellegrini. Ensaio sobre a processualidade. Fundamentos para uma nova teoria geral do processo. Brasília: Gazeta Jurídica, 2016, p. 62. DIDIER JR., Curso de Direito Processual, vol. 1, p. 220;

${ }^{29}$ SILVESTRI, Elisabetta. "Risoluzione delle Controversie e Alternative al Processo: Un'introduzione teórica". In: Elisabetta Silvestri (Org.). Forme alternative di risoluzione delle controversie e strumenti di giustizia riparativa. Torino: G. Giappichelli Editore, 2020, p. 2.

${ }^{30}$ JHERING, RUDOLF VON. Geist des römischen Rechts auf den verschiedenen Stufen seiner Entwicklung, Teil 2, Abteilung 2, Unveränderter Neudruck der 5. (lezten veränderten) Auflage Leipzig 1898, Aalen, Scientia Verlag, 1968, n. XXXVIII, p. 32, t. III, n. 43, p. 17, da edição espanhola de 1910, trad. Enrique Príncepe y
} 
Nesse sentido, a opção pela autocomposição em direitos coletivos transnacionais pode contribuir para a concretização de direitos coletivos transnacionais. O maior problema desses direitos é a efetividade da tutela obtida judicialmente, quando necessário o reconhecimento de sentença e execução em outro ordenamento jurídico. Isso porque a jurisdição é utilizada para obstar a efetividade da tutela jurisdicional transnacional, permitindo às grandes corporações transnacionais usufruírem de um verdadeiro "limbo" de irresponsabilidade global.

Esse "limbo" ocorre da seguinte forma: normalmente as violações a direitos humanos e danos ambientais ocorrem em país estrangeiro cuja jurisdição é menos protetiva aos direitos e tais violações são realizadas através de uma empresa-braço da corporação transnacional no exercício da atividade econômica. Assim, diante da existência de jurisdições concorrentes, as corporações transnacionais buscam, através do forum non conveniens, o argumento da força da conexão do local do dano ou do ilícito para que a jurisdição estatal seja fixada na jurisdição com menor proteção a direitos. Após o processo transcorrer na jurisdição menos protetiva, em caso de procedência da ação, quando essas corporações transnacionais são acionadas para o reconhecimento e execução da sentença estrangeira no ordenamento jurídico em que sua sede está localizada, alegam falhas no processo justo, evitando o reconhecimento e esquivando-se da responsabilização de seus atos diante de sentenças judiciais que não se concretizam no mundo dos fatos por falta de reconhecimento.

O "limbo" de irresponsabilidade global decorrente da lacuna de acesso à justiça transnacional (transnational access-to-justice gap) ${ }^{31}$ ocorre quando determinado ordenamento jurídico entende ser inadequado o exercício de sua jurisdição (no caso de jurisdições concorrentes), aplicando o forum non conveniens. Entretanto, após, quando acionado em eventual reconhecimento e execução de decisão estrangeira, o mesmo

\footnotetext{
Satorres, Madrid, Editorial Bailly-Bailliere apud OLIVEIRA, Carlos Alberto Alvaro de. Do Formalismo no processo civil. São Paulo: ed. Saraiva, 2003, p. 244.

31 WHYTOCK, Christopher A.; ROBERTSON, Cassandra Burke. "Forum Non Conveniens and the Enforcement of Foreign Judgments" (July 25, 2011). Columbia Law Review, Vol. 111, No. 7, 2011; UC Irvine School of Law Research Paper No. 2011-33; Case Legal Studies Research Paper No. 2011-16, 1520-1521. Disponível em SSRN: https://ssrn.com/abstract=1895011, acesso em 2.7.2017.
} 
Revista Eletrônica de Direito Processual - REDP.

Rio de Janeiro. Ano 16. Volume 23. Número 1. Janeiro a Abril de 2022

Periódico Quadrimestral da Pós-Graduação Stricto Sensu em Direito Processual da UERJ

Patrono: José Carlos Barbosa Moreira (in mem.). ISSN 1982-7636. pp. 213-235

www.redp.uerj.br

ordenamento jurídico afirma não ser possível o reconhecimento do julgado realizado no foro estrangeiro por problemas de falhas no processo justo. ${ }^{32}$

A autocomposição em processos coletivos transnacionais ganha importância justamente nesse contexto. Evidentemente que a obtenção de acordos, ainda que parciais, não é uma tarefa fácil.

Entretanto, o Ministério Público em nosso ordenamento jurídico, exerce o protagonismo na defesa de direitos coletivos e possui uma ferramenta importantíssima capaz de fomentar a autocomposição. Trata-se do inquérito civil que permite a busca por uma completude do material probatório bem ampla, favorecendo à solução autocompositiva do litígio.

Os acordos em processos coletivos transnacionais, por serem uma solução autocompositiva, por si só, já representam um importante instrumento à efetivação dos direitos, pois se trata de solução negociada ${ }^{33}$, e não imposta pelo método heterocompositivo tradicional. Evidentemente, que problemas na execução dos acordos existirão. A execução, contudo, tende a ter a vantagem de a autocomposição em direitos coletivos transnacionais ter uma natureza essencialmente contratual e depender, antes de mais nada, da vontade das partes para a obtenção da força obrigatória dos contratos. ${ }^{34}$

\footnotetext{
32 Idem, p. 1510-1514. Esse tipo de "limbo" de irresponsabilidade global é comum em danos ambientais transnacionais como caso Chevron Aguinda v. Texaco, Inc., 303 F.3d 470, 473 (2d Cir. 2002) que se arrasta por mais de 25 anos e ainda não foi solucionado. Em 2014, a justiça dos EUA declarou nula a sentença que mandava a Chevron indenizar os danos causados em US\$ 8.6 bilhões. Em junho de 2017, a Suprema Corte dos Estados Unidos decidiu não julgar um recurso apresentado contra a decisão da Corte de Apelação do Segundo Circuito, mantendo a decisão do juiz de Nova York que decidiu que a condenação da empresa se baseou em prova fraudulenta e que o advogado norte-americano Steven Donzinger teria cometido crimes para impor a sentença equatoriana nos Estados Unidos. Essa decisão implica grande vitória à Chevron (www.reuters.com/article/us-usa-court-chevron/u-s-top-court-hands-chevron-victory-in-ecuador-pollutioncase-idUSKBN19A1V4), pois impede o reconhecimento e execução da sentença equatoriana nos Estados Unidos. No Brasil também houve um pedido de homologação de sentença estrangeira por 47 pessoas em relação à referida sentença condenatória da Chevron realizada no Equador, sendo, contudo, rejeitada a homologação de sentença pela Corte Especial do STJ em 1.12.2017 (SENTENÇA ESTRANGEIRA CONTESTADA No 8.542 - EC (2013/0081095-1)). Portanto, depara-se com uma situação que ultrapassa mais de 20 anos sem que tenha havido qualquer solução para os danos causados. Sobre o caso Chevron, consultar: ZANETI JR, Hermes; BORGES, Orlindo Francisco; CARDOSO, Juliana Provedel. "Ações Coletivas Transnacionais para a tutela de danos ambientais: o caso Chevron (HSE n ${ }^{\circ}$ 8542). Revista de Direito Ambiental. São Paulo: RT, ano 21, nº 84, out/dez, 2016.

${ }^{33}$ Sobre uma visão de que a justiça nos métodos autocompositivos deve ser edificada pelas partes ver GORETTI, Ricardo. Mediação e acesso à Justiça. Salvador, Editora Jus Podivum, 2016, p. 61.

${ }^{34}$ KRAMER, Xandra E. "Securities Collective Action and Private International Law Issues in Dutch WCAM Settlements: Global Aspirations and Regional Boundaries" (March 1, 2014). Global Business \& Development Law Journal, Volume 27, Issue 2, pp. 235-279, 2014. Disponível em SSRN: https://ssrn.com/abstract=2480079, consultado em 21.4.2021, p. 20.
} 
Além disso, a articulação entre direito dos contratos e o processo justo ${ }^{35}$ visa a condução de acordos realizados com garantias que passam por uma "processualização do contrato" 36 , manifestada na totalidade de seus sentidos: processual e substancial, numa ideia de ciclo fechado ${ }^{37}$. Nesse sentido, busca-se evitar desequilíbrios manifestamente significativos e excessivos (abusos) nos $\operatorname{acordos}^{38}$, tais como aqueles realizados diante de uma relação de forças desiguais (quando há imposição de uma solução de uma parte à outra, por exemplo), pois acordos justos facilitam a execução em outro ordenamento jurídico, caso isso venha a ser necessário, evitando argumento de violação à ordem pública, por exemplo.

No Brasil, a homologação judicial dos acordos coletivos não é obrigatória. O Ministério Público, em nosso ordenamento, exerce o protagonismo na legitimação

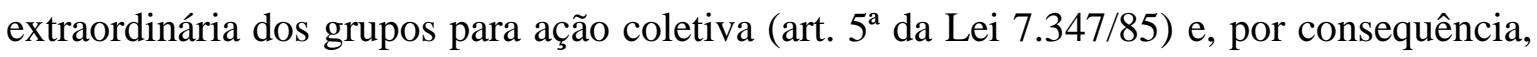
para autocomposição em ação coletiva. Exerce ainda o papel de fiscal do ordenamento jurídico (art. $5^{\circ}$, $2^{\circ}$, da Lei 7.347/1985), o que permite, desde já, um controle análogo ao do juiz na homologação, pois, mesmo quando seja parte, atua em nome do interesse público primário $^{39}$ que qualifica a tutela coletiva no interesse da coletividade, dos grupos.

No caso Odebrecht em Angola, não obstante não seja obrigatória a homologação, a autocomposição realizada foi homologada judicialmente, tornando-a título executivo judicial nos termos do art. 515, II e III, do Código de Processo Civil. Importante destacar

\footnotetext{
${ }^{35}$ Este trabalho utiliza "processo justo" que tem sua equivalência ao devido processo legal, previsto no art. $5^{\circ}$, LIV, CRFB (due process of law, procès equitáble, processo equo e giusto, fair), com expressa preocupação da inclusão de sua dimensão substancial. COMOGLIO, Luigi Paolo. Etica e técnica del "giusto processo”. Torino: G. Giappichelli Editore, 2004, p. 47-51; Devido processo legal ou processo justo não compreende somente a garantia de legalidade, mas de justiça (fair trial ou giudizio equo). PICARDI, Nicola. Manuale del processo civile. $3^{\mathrm{a}}$ ed. Milão: Giuffrè Editore, 2013, p. 4. SARLET, Ingo Wolfgang; MARINONI, Luiz Guilherme; MITIDIERO, Daniel. Curso de Direito Constitucional. São Paulo: Saraiva, 2016, p. 736-738; ÁVILA, Humberto. "O que é 'devido processo legal'?". Revista de Processo, v. 163, set./2008.

${ }^{36}$ CADIET, Loïc. "Les jeux du contrat et du procès". Mélanges offerts à Gérard Farjat. Éditions Frison-Roche, 1999, p. 23;

${ }^{37}$ CADIET, Loïc; NORMAND, Jacques; MEKKI, Soraya Amrani. Theórie générale du procès. $2^{\mathrm{a}}$ ed. Paris: Thémis droit, 2013, p. 241. No Brasil, ressaltando a processualização das obrigações: COUTO E SILVA, Clóvis. A obrigação como processo. Rio de Janeiro; FVG, 2006.

${ }^{38}$ CADIET, Loïc; NORMAND, Jacques; MEKKI, Soraya Amrani. Theórie générale du procès. $2^{\mathrm{a}}$ ed. Paris: Thémis droit, 2013, p. 218.

${ }^{39}$ MELLO, Celso Antonio Bandeira de. Curso de Direito Administrativo. 15 a ed. São Paulo: Malheiros, 2003, p. 603. No original, ALESSI, Renato. Sistema instituzionale del diritto ammisnistrativo italiano. Milano: Giuffrè, 1953, p. 148-155; DIDIER JR., Fredie; ZANETI JR., Hermes. Curso de Direito Processual Civil. $12^{\mathrm{a} e d . ~ S a l v a d o r: ~ J u s ~ P o d i v m, ~ 2018, ~ V o l . ~ 4, ~ p . ~ 41-43 ; ~ Z A N E T I, ~ G r a z i e l a ~ A r g e n t a . ~ J u r i s d i c ̧ a ̃ o ~ A d e q u a d a ~ p a r a ~}$ os Processos Coletivos Transnacionais. São Paulo: RT, 2020, p. 174.
} 
que o acordo ocorreu em segundo grau de Jurisdição, após sentença condenatória em primeiro grau e representou a "liberação" da culpa e redução do valor da condenação.

A autocomposição no caso Odebrecht em Angola se preocupou com o gerenciamento da ação coletiva transnacional de forma a obter efetividade da ação coletiva transnacional sem a necessidade de execução em outro ordenamento jurídico.

Mesmo nos casos em que o reconhecimento e a execução sejam necessários em outro ordenamento jurídico, a autocomposição, em razão de sua natureza contratual, representa uma vantagem em busca da efetivação de direitos que não se limitam as fronteiras nacionais, se compararmos à tradicional via do reconhecimento e execução de sentença estrangeira.

\section{CONSIDERAÇÕES FINAIS}

A partir da análise da autocomposição no caso Odebrecht em Angola demonstrou-se que a efetivação de direitos coletivos transnacionais pode ser pensada a partir de meios autocompositivos.

As dificuldades decorrentes da necessidade de reconhecimento e execução de sentença estrangeira são comuns num cenário transnacional, especialmente em ações coletivas que utilizam a técnica opt out semelhante às class actions. Nessas ações o reconhecimento (e a execução) de sentença estrangeira acarreta comumente problema de duração razoável do processo e do próprio reconhecimento. A rejeição de alguns ordenamentos jurídicos à técnica coletiva opt out é uma realidade, seja por inadmitirem a técnica opt out, seja por entenderem não ser cabível a regulação de matéria de direito público extraterritorialmente.

A ausência de reconhecimento e execução de um processo coletivo transnacional costumam ocasionar uma lacuna de acesso à justiça transnacional (transnational access-tojustice gap), ou seja, obtêm-se um direito que não se realiza no mundo dos fatos, restando apenas como palavras vazias no ar. Esse limbo jurídico de irresponsabilidade global decorrente do não reconhecimento e execução de sentença estrangeira significa uma grande vantagem econômica às grandes corporações transnacionais que evitam a responsabilização por danos, ambientais e humanos, por elas causados no exercício da atividade econômica, normalmente em países com uma frágil tutela de direitos 
Defendeu-se a importância do gerenciamento do processo coletivo desde a fixação da jurisdição mais adequada ao caso, passando pelos pedidos que devem constar na ação coletiva e que irão facilitar a efetivação dos direitos com menor obstáculo, caso seja necessário o envolvimento de outro ordenamento jurídico, bem como desenvolvendo um processo coletivo preocupado com a completude do material probatório. Isso porque o gerenciamento do processo nesse sentido tende a favorecer à uma resolução autocompositiva do conflito e, por consequência, favorecer à efetivação dos direitos coletivos transnacionais.

O caso Odebrecht em Angola foi um exemplo de resolução autocompositiva de um processo coletivo transnacional em que houve tal gerenciamento: a) definição da jurisdição no Brasil; b) a utilização de técnica coletiva opt out para a tutela dos direitos difusos existentes na situação jurídica coletiva para maior efetividade da tutela regulatória; c) produção de material probatório de modo a favorecer a resolução autocompositiva; d) realização de autocomposição com garantias no sentido de uma "processualização do contrato" de modo a não gerar problemas de ordem pública, caso o acordo tenha que ser executado em outro ordenamento jurídico.

A ideia de processualização da autocomposição significa que, em processos coletivos transnacional, o acordo não pode ser uma opção descomprometida com a justiça, sob pena de retrocesso na garantia dos direitos fundamentais, devendo ser pautado no sentido de uma passagem de um acesso à justiça formal para um acesso à justiça substancial. Isso exige a compreensão de que a ideia de acesso à justiça não se limita ao acesso à um meio de resolução de conflito, mas se volta, principalmente, para o acesso adequado à justiça. Dentro dessa concepção de adequação, a efetivação dos direitos coletivos transnacionais ainda é um grande desafio para os diferentes ordenamentos jurídicos que precisa ser superado. A autocomposição pode auxiliar na construção de pontes entre os ordenamentos jurídicos colaborando para esse vencer os desafios das limitações territoriais de cada país.

\section{REFER̂̂ENCIAS:}

ALESSI, Renato. Sistema instituzionale del diritto ammisnistrativo italiano. Milano: Giuffrè, 1953. 
ANDREWS Neil. "Multi-Party Proceedings in England: Representative and Group Actions". 11 Duke Journal of Comparative \& International Law 249-268 (2001), disponível em http://scholarship.law.duke.edu/djcil/vol11/iss2/5, acesso em 15.7.2017.

ARAÚJO, Nádia de. Direito Internacional Privado. Teoria e Prática Brasileira. $1^{\text {a }}$ ed. Porto Alegre: Revolução, eBook, 2016.

ÁVILA, Humberto. “O que é 'devido processo legal'?”. Revista de Processo, v. 163, set./2008.

BASSETT, Debra Lyn. “Class Action Silence”. Boston University Law Review, Vol. 94, No. 4, 2014, disponível em: https://ssrn.com/abstract=2533776, acesso em 10.7.2017.

BUSCHKIN, Ilana T. "The Viability of Class Action Lawsuits in a Globalized Economy Permitting Foreign Claimants to Be Members of Class Action Lawsuits in the U.S. Federal Courts". Cornell Law Review, Vol. 90, 2005. Disponível em SSRN: https://ssrn.com/abstract=2084220, acesso e 11.7.2017.

BUXBAUM, Hannah L. "Class Actions, Conflict and the Global Economy". Indiana Journal of Global Legal Studies, Vol. 21, Summer 2014; Indiana Legal Studies Research Paper no 301, disponível em SSRN: https://ssrn.com/abstract=2495521, acesso em 12.7.2017.

BUXBAUM, Hannah L. "Transnational Regulatory Litigation". Virginia Journal of International Law, Vol. 46, 2006. Disponível em SSRN: https://ssrn.com/abstract=910185, acesso em 5.7.2017.

CABRAL, Antônio do Passo. "Incidente de Resolução de demandas Repetitivas". Comentários ao Novo Código de Processo Civil. Antonio do Passo Cabral e Ronaldo Cramer (coord.). Rio de Janeiro: Forense, 2015.

CADIET, Loïc. "Les jeux du contrat et du procès“. Mélanges offerts à Gérard Farjat. Éditions Frison-Roche, 1999.

CADIET, Loïc; NORMAND, Jacques; MEKKI, Soraya Amrani. Theórie générale du procès. $2^{\mathrm{a}}$ ed. Paris: Thémis droit, 2013.

COMOGLIO, Luigi Paolo. Etica e técnica del "giusto processo". Torino: G. Giappichelli Editore, 2004; PICARDI, Nicola. Manuale del processo civile. $3^{\mathrm{a}}$ ed. Milão: Giuffrè Editore, 2013. 
COSTA E SILVA, Paula. A Nova Face da Justiça. Os Meios Extrajudiciais de Resolução de Controvérsias. Lisboa: Coimbra Editora, 2009.

COUTO E SILVA, Clóvis. A obrigação como processo. Rio de Janeiro; FVG, 2006.

DIDIER JR., Fredie. Curso de Direito Processual Civil. 17ª ed. Salvador: JusPodivm, 2015, Vol. 1.

DIDIER JR., Fredie; ZANETI JR. Hermes. "Conceito de Processo Jurisdicional Coletivo”. RePro, São Paulo: RT, nº 229, mar. 2014.

DIDIER JR., Fredie; ZANETI JR., Hermes. Curso de Direito Processual Civil. 12a ed. Salvador: JusPodivum, 2018, vol. 4.

DIDIER JR., Fredie; ZANETI JR., Hermes. Curso de Direito Processual Civil. Processo Coletivo. Vol. 4. 14ª ed. Salvador: JusPodivm, 2020.

GARNER, Bryan A. Black's Law Dictionary, 2 ${ }^{a}$ pocket ed. West Group, 2001.

GIDI, Antonio. A Class Action como instrumento de tutela coletiva dos direitos. São Paulo: Revista dos Tribunais, 2007.

GORETTI SANTOS, Ricardo. Gestão Adequada de Conflitos: do diagnóstico à escolha do método adequado para cada caso concreto. 1. ed. Salvador: JusPodivm, 2019. v. 1.

GORETTI, Ricardo. Mediação e acesso à Justiça. Salvador, Editora Jus Podivum, 2016.

GRINOVER, Ada Pellegrini. Ensaio sobre a processualidade. Fundamentos para uma nova teoria geral do processo. Brasília: Gazeta Jurídica, 2016.

HILL, Flávia Pereira. A antecipação da tutela no processo de homologação de sentença estrangeira. Rio de Janeiro: GZ Editora, 2010.

HILL, Flávia Pereira. O Direito Processual Transnacional como forma de acesso à justiça no Século XXI: os reflexos e desafios da sociedade contemporânea para o Direito Processual Civil e a concepção de um título executivo transnacional. Rio de Janeiro: GZ Editora, 2013.

HODGES, Christopher J. S. Multi-party actions. Oxford: Oxford University Press, 2001.

KRAMER, Xandra E. "Securities Collective Action and Private International Law Issues in Dutch WCAM Settlements: Global Aspirations and Regional Boundaries" (March 1, 2014). Global Business \& Development Law Journal, Volume 27, Issue 2, pp. 235279, 2014. Disponível em SSRN: https://ssrn.com/abstract=2480079, consultado em 21.4.2021. 
LEITE, Carlos Henrique Bezerra. Manual de Direitos Humanos. 3. ed. São Paulo: Atlas, 2014. v. 1.

LEITE, Carlos Henrique Bezerra. "Acesso coletivo à justiça como instrumento para efetivação dos direitos humanos: por uma nova mentalidade". Revista do Tribunal Regional do Trabalho da $15^{a}$ Região, n. 35, 2009, p. 94., disponível em https://juslaboris.tst.jus.br/bitstream/handle/20.500.12178/104849/2009_leite_carlo s_acesso_coletivo.pdf?sequence=1\&isAllowed=y, acesso em 21.4.2021.

LEITE, Carlos Henrique Bezerra. Curso de Direito Processual do Trabalho. $19^{a}$ ed. São Paulo: Saraiva, 2021.

MELLO, Celso Antonio Bandeira de. Curso de Direito Administrativo. 15 ${ }^{\mathrm{a}}$ ed. São Paulo: Malheiros, 2003.

MONESTIER, Tanya J. "Transnational Class Actions and the Illusory Search for Res Judicata". Tulane Law Review, Vol. 86, 2011; Roger Williams Univ. Legal Studies Paper $\mathrm{n}^{\circ}$ 105. Disponível em SSRN: https://ssrn.com/abstract=1853773, acesso em 8.7.2017.

MOSCHEN, Valesca Raizer Borges; ZANETI, Graziela A.. "Processo Internacional Transfronteiriço: os litígios que não respeitam fronteiras - da soberania à tutela dos direitos”. In: Bruno Manoel Viana; Valesca Raizer Borges Moschen;Valter Moura do Carmo. (Org.). Direito Internacional II. $1^{\mathrm{a}}$ ed. Florianópolis: CONPEDI, 2016, v. 1.

NERY JR., Nelson. Código Brasileiro de Defesa do Consumidor: comentado pelos autores do anteprojeto. Rio de Janeiro: Forense Universitária. 1998.

OLIVEIRA, Carlos Alberto Alvaro de. Do Formalismo no processo civil. São Paulo: ed. Saraiva, 2003.

PINNA, Andrea. "Recognition and Res Judicata of U.S. Class Action Judgments in European Legal Systems”. Erasmus Law Review, Vol. 1, No. 2, 2008. Disponível em SSRN: https://ssrn.com/abstract=1018421, acesso em 16.7.2017.

SARLET, Ingo Wolfgang; MARINONI, Luiz Guilherme; MITIDIERO, Daniel. Curso de Direito Constitucional. São Paulo: Saraiva, 2016.

SILVESTRI, Elisabetta. "Risoluzione delle Controversie e Alternative al Processo: Un'introduzione teórica". In: Elisabetta Silvestri (Org.). Forme alternative di 
risoluzione delle controversie e strumenti di giustizia riparativa. Torino: G. Giappichelli Editore, 2020.

TIBURCIO, Carmen. Extensão e limites da Jurisdição Brasileira. Competência Internacional e Imunidade de Jurisdição. Salvador: Jus Podivm, 2016.

WHYTOCK, Christopher A. "The Evolving Forum Shopping System”, 96 Cornell L. Rev. 481, $486 \quad$ (2011). $\quad$ Disponível em http://scholarship.law.cornell.edu/cgi/viewcontent.cgi?article=3195\&context=clr, acesso em 1.7.2017.

WHYTOCK, Christopher A.; ROBERTSON, Cassandra Burke. "Forum Non Conveniens and the Enforcement of Foreign Judgments" (July 25, 2011). Columbia Law Review, Vol. 111, No. 7, 2011; UC Irvine School of Law Research Paper No. 2011-33; Case Legal Studies Research Paper No. 2011-16, 1520-1521. Disponível em SSRN: https://ssrn.com/abstract=1895011, acesso em 2.7.2017.

ZANETI JR, Hermes; BORGES, Orlindo Francisco; CARDOSO, Juliana Provedel. “Ações Coletivas Transnacionais para a tutela de danos ambientais: o caso Chevron (HSE ${ }^{\circ}$ 8542)". Revista de Direito Ambiental. São Paulo: RT, ano 21, nº 84, out/dez, 2016.

ZANETI JR., Hermes. O “novo” mandado de segurança coletivo. Salvador: Jus Podivum, 2013.

ZANETI, Graziela Argenta. Jurisdição adequada para os processos coletivos transnacionais. São Paulo: RT, 2020. 